\title{
Prognostic value of platelet recovery degree before and after achieving minimal residual disease negative complete remission in acute myeloid leukemia patients
}

Yang Wang ${ }^{1,2 \dagger}$, Hua Wang ${ }^{1,2+}$, Weida Wang ${ }^{1,2}$, Wenjian Liu ${ }^{1,2}$, Nawei Liu ${ }^{1,2}$, Shuang Liu ${ }^{1,2}$ and Yue Lu ${ }^{1,2^{*}}$ (D)

\begin{abstract}
Background: Risk stratification and prognosis prediction of acute myeloid leukemia (AML) are largely dependent on pre-treatment information. However, post-treatment data also provides much useful information. In this retrospective study, we explored whether the level of blood count recovery before and after the first minimal residual disease (MRD) negative complete remission (CR) is relevant to clinical outcomes of AML patients.

Methods: For each included patient, peripheral platelet counts were measured on the day before initial treatment $\left(P L T_{\text {pre }}\right)$, whereas platelet peak values ( $P L T_{\text {peak }}$ ) were recorded after marrow recovery following the chemotherapy course inducing the first MRD-negative $C R$. The difference $\left(D_{P L T}\right)$ between these two values $\left(D_{P L T}=P L T_{\text {peak }} P L T_{\text {pre }}\right)$ was calculated. X-tile software was utilized to establish the optimal cut-point for $D_{\text {PLT, }}$ which was expected to distinguish CR patients with different clinical outcomes. A cross validation analysis was conducted to confirm the robustness of the established cut-point. The results were further tested by a Cox multivariate analysis.

Results: The optimal cut-point of DPLT was determined as $212 \times 10^{9} / \mathrm{L}$. Patients in high $D_{P L T}$ group were observed to have a significantly better PFS $(p=0.016)$ and a better OS (without statistical significance, $p=0.106)$. Cox multivariate analysis showed that higher DPLT was associated with longer PFS (HR=2.894, 95\% Cl: 1.320-6.345, $p=$ 0.008 ) and longer $\mathrm{OS}(\mathrm{HR}=3.077,95 \% \mathrm{Cl}: 1.130-8.376, p=0.028)$.

Conclusion: Platelet recovery degree before and after achieving MRD-negative CR ( $\left.D_{P L T}\right)$ is a potential predictor of

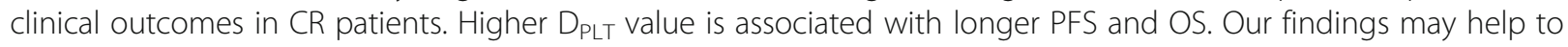
develop simple methods for AML prognosis evaluation.
\end{abstract}

Keywords: Acute myeloid leukemia (AML), Complete remission (CR), Platelet recovery degree, Progression free survival (PFS), Overall survival (OS)

\footnotetext{
* Correspondence: Ivyue@sysucc.org.cn

${ }^{\dagger}$ Yang Wang and Hua Wang contributed equally to this work.

'Department of Hematologic Oncology, Sun Yat-sen University Cancer

Center, 651 Dongfengdong Rd, Guangzhou 510060, China

${ }^{2}$ State Key Laboratory of Oncology in Southern China, Collaborative

Innovation Center for Cancer Medicine, Guangzhou 510060, China
}

(C) The Author(s). 2020 Open Access This article is licensed under a Creative Commons Attribution 4.0 International License, which permits use, sharing, adaptation, distribution and reproduction in any medium or format, as long as you give appropriate credit to the original author(s) and the source, provide a link to the Creative Commons licence, and indicate if changes were made. The images or other third party material in this article are included in the article's Creative Commons licence, unless indicated otherwise in a credit line to the material. If material is not included in the article's Creative Commons licence and your intended use is not permitted by statutory regulation or exceeds the permitted use, you will need to obtain permission directly from the copyright holder. To view a copy of this licence, visit http://creativecommons.org/licenses/by/4.0/ The Creative Commons Public Domain Dedication waiver (http://creativecommons.org/publicdomain/zero/1.0/) applies to the data made available in this article, unless otherwise stated in a credit line to the data. 


\section{Background}

Acute myeloid leukemia (AML) is a highly heterogeneous disease, for which precise diagnosis and risk stratification is crucial. Currently the best diagnostic methods for AML include morphologic, flow cytometric, cytogenetic and molecular examination (sometimes bone marrow biopsy is also needed). A combination of these examinations presents a relatively comprehensive understanding of the disease $[1,2]$. On the other hand, discovering new biomarkers associated with prognosis and exploring their relationship with clinical outcomes have become the focus of researches. In addition to pretreatment information, some types of post-treatment information, such as minimal residual disease (MRD) [3, 4], response to first induction chemotherapy [5], and repeated bone marrow examination (morphologic, cytogenetic, flow cytometric, or molecular) during or after treatment courses [6-8] are also reported to be informative. As the embodiment of "real response" to standard therapy, post-treatment data should be carefully considered. It is a necessary complement for prognosis evaluation. For example, although more than $50 \%$ of newly diagnosed AML patients will achieve CR after standard induction chemotherapy, a large proportion of them will relapse and eventually die after different durations of CR [9]. Thus, the predictive factor of this difference among CR patients should be further identified. In this study, patients achieving MRD-negative CR were included. We calculated the platelet count changes between 'before treatment' and 'after achieving the first MRD-negative CR' (D $\mathrm{DLT}_{\text {PLT }}$ ) for each patient, and explored whether or not this platelet change is potentially predictive of progression-free survival (PFS) or overall survival (OS) in these patients.

\section{Methods}

\section{Patients and methods}

A total of 105 patients newly diagnosed with AML (M3 and myeloid sarcoma excluded) in the Sun Yat-sen University Cancer Center from 2002.10 to 2016.12 were enrolled in this study. The diagnosis was based on the 2002 World Health Organization (WHO) criteria [10]. All patients received standard induction chemotherapy containing cytarabine and DNR/IDR (DNR $50 \mathrm{mg} / \mathrm{m}^{2}$, $\mathrm{d} 1-3+$ Ara-C $100 \mathrm{mg} / \mathrm{m}^{2}, \mathrm{~d} 1-7$; or IDA $12 \mathrm{mg} / \mathrm{m}^{2}, \mathrm{~d} 1-$ $3+$ Ara $-\mathrm{C} 100 \mathrm{mg} / \mathrm{m}^{2}$, d1-7). Among the 105 patients, 38 never achieved MRD-negative CR or died of complications in induction chemotherapy courses, while the other 67 obtained MRD-negative CR after one, two or three courses of induction therapy. MRD was detected with multiparametric flow cytometry (MFC) [7]. The sensitivity of the MRD assay was $0.01 \%$. All patients who achieved MRD-negative CR also met the criteria of the widely used morphological definition of CR: the presence of $<5 \%$ blasts in the bone marrow, the absence of extramedullary disorders, the recovery of neutrophil counts $>1 \times 10^{9} / \mathrm{L}$, and the platelet count $>100 \times 10^{9} / \mathrm{L}$ in the peripheral blood. All of these 67 patients then acquired consolidation therapy, among whom 32 received JALSG AML-201 regimen [11], 24 received AML-87 regimen [12], and 11 received High Dose Ara-C regimen [13]. After consolidation therapy was accomplished, follow-up was conducted and prognostic information (PFS and OS) was obtained. This study was approved by the Ethical committee of Sun Yat-sen University Cancer Center. Informed consent was obtained from all individual patients included in the study. All experiments were performed in accordance with the ethical standards of Declaration of Helsinki.

For each of the 67 MRD-negative CR patient, we measured peripheral platelet count on the day before initial treatment (denoted as $\mathrm{PLT}_{\text {pre }}$ ), and platelet peak value after marrow recovery following the chemotherapy course that induced the first MRD-negative CR (denoted as $\left.\mathrm{PLT}_{\text {peak }}\right)$. $\mathrm{PLT}_{\text {peak }}$ appeared during 28-35 days from the first day of the chemotherapy course in all enrolled patients. Then the difference (denoted as $\mathrm{D}_{\text {PLT }}$ ) between these two values $\left(\mathrm{D}_{\mathrm{PLT}}=\mathrm{PLT}_{\text {peak }}-\mathrm{PLT}_{\text {pre }}\right)$ was calculated. Based on corresponding survival data, we searched for an optimal cut-point of $\mathrm{D}_{\mathrm{PLT}}$ by x-tile software (Version: 3.6.1, Copyright Yale University 2003-05) [14, 15] to further distinguish prognosis. To avoid statistical bias introduced by 'multiple cut-off selection', a cross validation was conducted to test the robustness of the established cut-point [16, 17] (See 'Result' part and Fig. 1).

Among the 67 patients, single-course-CR patients (43 cases) were expected to have less marrow function impairment than multiple-course-CR patients (24 cases). We compared the mean of $\mathrm{D}_{\mathrm{PLT}}$ and PLT $\mathrm{P}_{\text {peak }}$ between the two groups. As we included patients needing 1 to 3 cycles to achieve MRD-negative CR in our study, we first tested whether or not there was significant difference of prognosis between single and multiple-course-CR patients. Secondly, we isolated the 43 single-course-CR patients and determine the optimal cut-point of $D_{\text {PLT }}$ by,the same method as above. We compared the predictive strength of $D_{\text {PLT }}$ and the number of courses to achieve CR.

After establishing the cut-point, survival analysis was conducted to test whether there is significant difference of PFS or OS between high and low D $\mathrm{DLT}_{\text {groups, and }}$ whether $D_{\text {PLT }}$ is an independent indicator for AML prognosis.

\section{Survival analysis}

PFS is defined as the time from the date of achieving the first MRD-negative CR to the date of relapse or death (with no definite record of relapse). OS is defined as the 


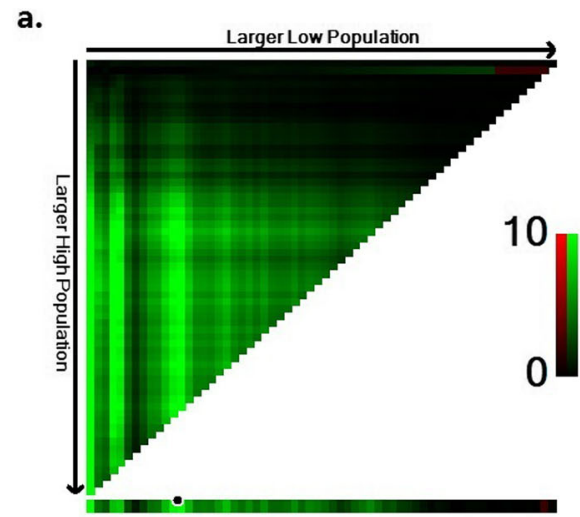

c.

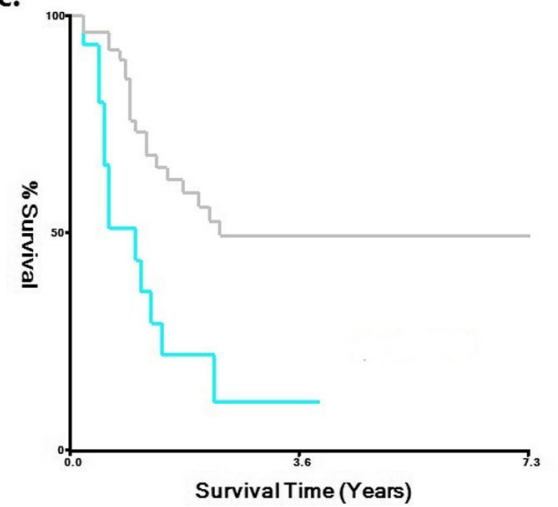

b.

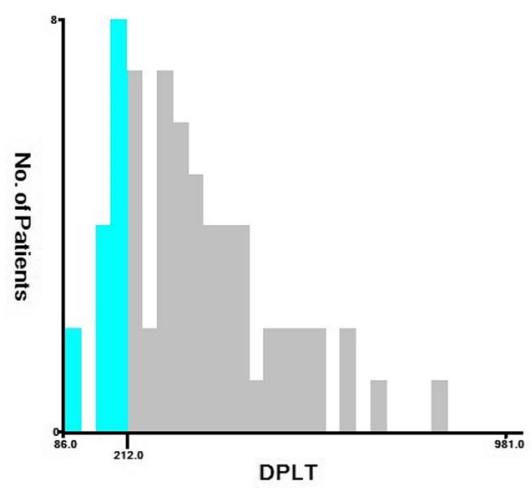

d.

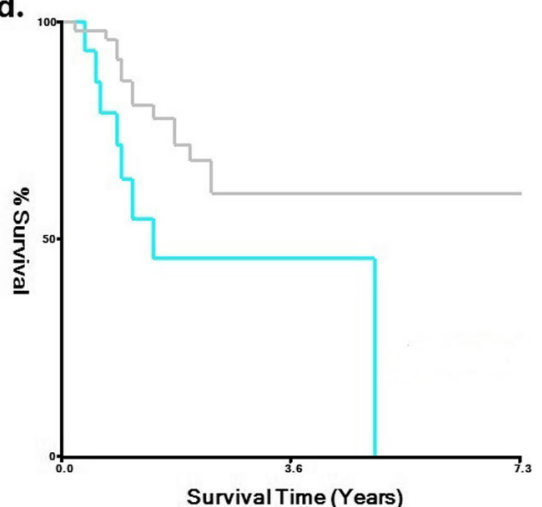

Fig. 1 X-tile analysis of survival data of 67 included patients. Every pixel of the plot represents the $x^{2}$ log-rank value generated from corresponding division of the data. Direct associations between DPLT and survival (higher D DLT indicates a better outcome) are colored green, whereas indirect associations (higher DPLT indicates poorer outcome) are colored red. A brighter (green or red) pixel color represents a larger $x^{2}$ log-rank value and a stronger association. a. Determination of the optimal cut-point. Survival data used for cut-point optimization is PFS. The optimal cut-point $\left(D_{P L T}=212 \times 10^{9} / \mathrm{L}\right)$ appears at the brightest pixel (The black dot on the straight line below). b. A histogram showing the distribution of the entire cohort and the established cut-point. c. Kaplan-Meier curve of PFS between high and low DPLT groups. The cutoff value is $D_{P L T}=212 \times 10^{9} / \mathrm{L}$. A significantly better PFS is observed in high $D_{P L T}$ group ( $p$-value given by cross-validation is 0.016 . The blue line represents for low $D_{P L T}$ group while the gray line represents for high $D_{P L T}$ group) $\mathbf{d}$. Kaplan-Meier curve of OS between high and low $D_{P L T}$ groups. The cutoff value is $D_{P L T}=212 \times 10^{9} / \mathrm{L}$. A better OS is observed in high DPLT group, but without significance ( $p$ value given by cross validation is 0.106 . The blue line represents for low DPLT group and the gray line represents for high DPLT group)

time from the date of achieving the first MRD-negative $\mathrm{CR}$ to the date of death. The optimal cut-point of $\mathrm{D}_{\text {PLT }}$ was established by $\mathrm{x}$-tile software (Version: 3.6.1, Copyright Yale University 2003-05), then a cross validation analysis as reported by Faraggi and Simon [17] was applied to test its significance. Specifically, a two-folded cross-validation was conducted. The whole dataset was randomly split into two subsets with equal size (Subset A and $\mathrm{B}$ ). In subset $\mathrm{A}$, we searched for the cutoff value with minimal two-sided log-rank $p$-value. Using this value, we divided subset B into two groups ('above cut-point' group and 'below cut-point' group). Similarly, in subset B we searched for the cutoff value with minimal two-sided logrank $p$-value, and divided subset A into 'above cut-point' group and 'below cut-point' group according to this value. Now every patient in the whole dataset was assigned into either 'above cut-point' group or 'below cut-point' group.
Then the log-rank Chi-square value and corresponding $p$ value stratified by subset $A$ and $B$ was calculated to test the significance of the established cut-point.

Based on the cut-point, the 67 patients were divided into 2 subgroups (high- $\mathrm{D}_{\text {PLT }}$ and low- $\mathrm{D}_{\text {PLT }}$ ). Categorical baseline features of the two subgroups were compared using $X^{2}$ test/Pearson chi-square test, whereas numerical ones were compared using a non-parametric Mann-Whitney U-test. Survival data was analyzed with Kaplan-Meier methodology, and the differences between groups were evaluated with a log-rank test. Cox multivariate regression analysis was used to test whether or not $D_{\text {PLT }}$ is an independent predictor of PFS or OS after considering some potential prognostic covariates, including gender, age, cytogenetic risk, the number of chemotherapy courses needed to achieve MRD-negative $C R$, and consolidation regimen. 


\section{Results}

\section{Patient characteristics}

Clinical and laboratory information of the 67 included patients at diagnosis is shown in Table 1. Among the 67 patients, 33 were male, and 34 were female. Median age at diagnosis was 40.0 years (range of 3-69 years). According to $2016 \mathrm{WHO}$ diagnosis and risk stratification system of AML [2], 12 patients were classified as

Table 1 Clinical characteristics and laboratory test data of the 67 patients achieving MRD-negative CR

\begin{tabular}{|c|c|}
\hline Characteristics & \\
\hline \multicolumn{2}{|l|}{ Age (year) } \\
\hline Median & 40.0 \\
\hline Range & $3-69$ \\
\hline \multicolumn{2}{|l|}{ Sex } \\
\hline Male & 33 \\
\hline Female & 34 \\
\hline \multicolumn{2}{|c|}{ Initial White cell count $\left(10^{9} / \mathrm{L}\right)$} \\
\hline Median & 21.2 \\
\hline Range & $0.7-296.4$ \\
\hline \multicolumn{2}{|c|}{ Initial Hemoglobin (g/L) } \\
\hline Median & 77.0 \\
\hline Range & $39-144$ \\
\hline \multicolumn{2}{|c|}{ Initial Platelet Count $\left(10^{9} / \mathrm{L}\right)$} \\
\hline Median & 43.0 \\
\hline Range & $3-282$ \\
\hline \multicolumn{2}{|c|}{ Bone Marrow Blasts (\%) } \\
\hline Median & 66.5 \\
\hline Range & 22.9-98 \\
\hline \multicolumn{2}{|l|}{ Risk Group (No.) } \\
\hline Favorable & 12 \\
\hline Intermediate & 42 \\
\hline Adverse & 13 \\
\hline \multicolumn{2}{|c|}{ Courses needed to achieve MRD-negative CR } \\
\hline 1 & 43 \\
\hline 2 & 21 \\
\hline 3 & 3 \\
\hline \multicolumn{2}{|c|}{ Consolidation Regimen } \\
\hline AML-201 & 32 \\
\hline AML-87 & 24 \\
\hline HDAra-C & 11 \\
\hline \multicolumn{2}{|c|}{ Peak Platelet Count $\left(\mathrm{PLT}_{\text {peak }}, 10^{9} / \mathrm{L}\right)$} \\
\hline Median & 389. \\
\hline Range & $122-984$ \\
\hline \multicolumn{2}{|l|}{$D_{\text {PLT }}\left(10^{9} / L\right)$} \\
\hline Median & 328 \\
\hline Range & $86-981$ \\
\hline
\end{tabular}

favorable cytogenetics, 13 as adverse cytogenetics, and the remaining 42 as intermediate risk. At the time of diagnosis, median WBC count was $21.2 \times 10^{9} / \mathrm{L}$ (range of 0.7-296.4), median hemoglobin level was $77 \mathrm{~g} / \mathrm{L}$ (range of 39-144), and median platelet level was $43 \mathrm{X}$ $10^{9} / \mathrm{L}$ (range of $3-282$ ) (Table 1 ). Forty-three patients achieved MRD-negative CR after 1 course of induction therapy, twenty-one after 2 courses, and three after 3 courses. During marrow recovery after the chemotherapy course that induced the first MRD-negative CR, median platelet peak value $\left(\mathrm{PLT}_{\text {peak }}\right)$ was $389 \mathrm{X} 10^{9} / \mathrm{L}$ (range of 122-984), and median $\mathrm{D}_{\mathrm{PLT}}$ was $328 \times 10^{9} / \mathrm{L}$ (range of 86-981) (Table 1). Mean follow-up time was 29 months (range of 5-90 months). Two-year PFS and OS rates of all the 67 patients were 48.1 and $63.5 \%$, respectively. Three-year PFS and OS rates were 40.6 and $57.4 \%$, respectively.

\section{Prognosis analysis for survival}

Notice that there are two available survival datasets for determination of the optimal cut-point: PFS and OS. For PFS, the optimal cut-point is $\mathrm{D}_{\mathrm{PLT}}=212 \times 10^{9} / \mathrm{L}$ (statistically significant, Chi-square value is 5.833 , and $p$-value is 0.016 given by cross validation), while for OS no cutpoint with statistical significance was found ( $\mathrm{p}$-value is 0.106) (See Fig. 1). We then choose the cut-point as $\mathrm{D}_{\text {PLT }}=212 \times 10^{9} / \mathrm{L}$ for following analysis. Based on this value, all the 67 patients were divided into high and low $\mathrm{D}_{\text {PLT }}$ groups. The characteristics of patients in these two subgroups are shown in Table 2. No significant difference was observed between the two subgroups in terms of distribution of gender, age, cytogenetic risk, consolidation regimen, and the number of chemotherapy courses needed to achieve MRD-negative CR.

We found that patients in high $\mathrm{D}_{\text {PLT }}$ group had significantly better PFS (2-year PFS rate $56.3 \%$ versus $22.2 \%$, 3year PFS rate $49.7 \%$ versus $11.1 \%$; cross validation $p$ value $=0.016$.) and better OS, although without statistical significance (2-year OS rate $68.5 \%$ versus $45.9 \%$, 3year OS rate $60.9 \%$ versus $45.9 \%$; cross validation pvalue $=0.106)($ Fig. $1 \mathrm{c}$ and $\mathrm{d})$.

Furthermore, by conducting a multivariate analysis of PFS and OS, we found that high $\mathrm{D}_{\mathrm{PLT}}$ is an independent predictor of better prognosis. For PFS, HR $=2.894$, 95\% confidence interval $1.320-6.345, p=0.008$. For OS, the variables were $\mathrm{HR}=3.077,95 \%$ confidence interval: 1.130-8.376, $p=0.028$ (See Table 3).

\section{Comparative analysis of single-course-CR and multiple- course-CR patients}

In our study, 43 single-course-CR patients and 24 multiple-course-CR patients were included. No significant difference was found in platelet counts before treatment initiation $(p$-value $=0.663)$. According to our data, 
Table 2 Clinical characteristics and laboratory test data of patients in high DPLT group and low D DLT group (Cutoff value: $\left.D_{\text {PLT }}=212 \times 10^{9} / \mathrm{L}\right)$

\begin{tabular}{|c|c|c|c|}
\hline Characteristics & $\begin{array}{l}\text { High DPLT Group } \\
(n=52)\end{array}$ & $\begin{array}{l}\text { Low DPLT Group } \\
(n=15)\end{array}$ & $\boldsymbol{p}$ value \\
\hline \multicolumn{4}{|l|}{ Age (year) } \\
\hline Median & 38.5 & 42.0 & \multirow[t]{2}{*}{0.144} \\
\hline Range & $3-69$ & $20-67$ & \\
\hline \multicolumn{4}{|l|}{ Sex } \\
\hline Male & 24 & 9 & \multirow[t]{2}{*}{0.345} \\
\hline Female & 28 & 6 & \\
\hline \multicolumn{4}{|c|}{ Initial White cell count $\left(10^{9} / \mathrm{L}\right)$} \\
\hline Median & 18.3 & 45.3 & \multirow[t]{2}{*}{0.299} \\
\hline Range & $0.7-296.41$ & $1.04-149$ & \\
\hline \multicolumn{4}{|l|}{ Risk Group (No.) } \\
\hline Favorable & 10 & 2 & \multirow[t]{3}{*}{0.870} \\
\hline Intermediate & 32 & 10 & \\
\hline Adverse & 10 & 3 & \\
\hline \multicolumn{4}{|c|}{ Courses needed to achieve MRD-negative CR } \\
\hline 1 & 36 & 7 & \multirow[t]{3}{*}{0.092} \\
\hline 2 & 15 & 6 & \\
\hline 3 & 1 & 2 & \\
\hline \multicolumn{4}{|c|}{ Consolidation Regimen } \\
\hline AML-87 & 18 & 6 & \multirow[t]{3}{*}{0.783} \\
\hline AML-201 & 26 & 6 & \\
\hline HD Ara-C & 8 & 3 & \\
\hline
\end{tabular}

patients achieving MRD-negative CR with 1 course had a significantly higher platelet peak value $\left(\mathrm{PLT}_{\text {peak }}\right)$ as well as platelet difference $\left(D_{\text {PLT }}\right)$ compared to patients with more courses. For single-course-CR patients $\mathrm{D}_{\mathrm{PLT}}=$ $(388.0 \pm 176.3) \times 10^{9} / \mathrm{L}$, while for multiple-course-CR patients $\mathrm{D}_{\mathrm{PLT}}=(300.6 \pm 153.5) \times 10^{9} / \mathrm{L} \quad(p$-value $=0.046)$. For single-course-CR patients PLT $_{\text {peak }}=(456.4 \pm$ $161.5) \times 10^{9} / \mathrm{L}$, while for multiple-course-CR patients $\mathrm{PLT}_{\text {peak }}=(358.0 \pm 165.6) \times 10^{9} / \mathrm{L}(\mathrm{p}$-value $=0.021)$. However, no significant difference of PFS or OS was observed between the two groups by Kaplan-Meier method. ( $p=$ 0.322 for PFS and $p=0.309$ for OS) .

Next, to clarify if these differences also manifest in differential treatment outcome, we isolated the 43 singlecourse-CR patients, and searched for an optimal cutpoint by $\mathrm{x}$-tile software in this subgroup of patients. Among the 43 single-course-CR patients no statistically significant cut-point was found ( $p$-value given by cross validation is 0.157 for PFS and 0.312 for OS). Because significant difference of clinical outcomes was found between high- and low- $\mathrm{D}_{\text {PLT }}$ subgroups rather than singleand multiple-course-CR subgroups, and there was no evidence for a different distribution of induction course number between high- and low- $\mathrm{D}_{\mathrm{PLT}}$ subgroups, we speculate that the number of induction cycles to achieve $C R$ is less informative than our new index $D_{\text {PLT }}$ concerning AML prognosis.

\section{Discussion}

A whole set of diagnostic methods, including at least morphologic, flow cytometric, cytogenetic, and molecular examination, is necessary to make a precise diagnosis for AML. Pre-treatment information from patients is undoubtedly the footstone to form an overview of the disease and select the proper way of treatment. On the other hand, post-treatment information, such as MRD, can be regarded as "true response" rather than "prediction." These data helps to adjust the treatment plan according to the real condition of patients $[18,19]$. Some related concepts, such as clonal evolution [20], have provided the most profound understanding of the disease. Thus, post-treatment information and instant changes during treatment should be carefully considered. This study focused on post-treatment information.

Some previous studies reported that high blood cell counts after CR (morphological definition) are predictive of longer PFS and OS $[21,22]$. In the current study, we strictly selected patients who achieved MRD-negative $\mathrm{CR}$, and examined whether or not a high level of platelet recovery is still predictive of a better prognosis under such a stricter criterion of CR. We speculate that CR is possibly a continuous process with different degrees rather than an "either-or" question. Degree of CR is a reasonable powerful predictor of PFS and OS, which importance should be noted. However, accurate measurement of it is still inaccessible due to limitations of existing methodologies.

In our study, both single-course-CR and multiplecourse-CR patients were included, among whom singlecourse-CR patients had significantly higher PLT $\mathrm{T}_{\text {peak }}$ and $\mathrm{D}_{\mathrm{PLT}}$ levels. However, survival analysis by Kaplan-Meier method showed no significant difference of PFS or OS between these two subgroups. According to our data, the number of courses to achieve CR is a minor factor of influence, which by itself is not sufficient to distinguish differential clinical outcomes. In contrast, significant difference emerges when we choose $D_{\text {PLT }}$ as the prognosis indicator. $\mathrm{D}_{\text {PLT }}$ appears to be able to stratify for differences in treatment outcome and therefore have prognostic value, whereas the number of induction cycles is less informative in comparison.

To select patients with MRD-negative CR, we had to apply stringent selection criteria, which limited the number of patients included in this study. As a result, some constraints of this study merit attention. Firstly, the size of each group is relatively small, thereby restricting the choice of study designs. An independent validation 
Table 3 Results of analysis of risk factors for PFS and OS

\begin{tabular}{|c|c|c|c|c|c|c|c|c|}
\hline \multirow[t]{3}{*}{ Factors } & \multicolumn{4}{|l|}{ PFS } & \multicolumn{4}{|l|}{ OS } \\
\hline & \multicolumn{2}{|l|}{ univariate } & \multicolumn{2}{|l|}{ multivariate } & \multicolumn{2}{|l|}{ Univariate } & \multicolumn{2}{|l|}{ multivariate } \\
\hline & $\mathrm{HR}(95 \% \mathrm{Cl})$ & $P$ value & $\mathrm{HR}(95 \% \mathrm{Cl})$ & $P$ value & $\mathrm{HR}(95 \% \mathrm{Cl})$ & $P$ value & $\mathrm{HR}(95 \% \mathrm{Cl})$ & $P$ value \\
\hline $\begin{array}{l}\text { Age } \\
\text { (As a numerical variate) }\end{array}$ & $\begin{array}{l}1.013 \\
(0.991-1.036)\end{array}$ & 0.247 & $\begin{array}{l}1.008 \\
(0.982-1.034)\end{array}$ & 0.559 & $\begin{array}{l}1.011 \\
(0.984-1.038)\end{array}$ & 0.429 & $\begin{array}{l}0.998 \\
(0.969-1.027)\end{array}$ & 0.871 \\
\hline \multicolumn{9}{|l|}{ Sex } \\
\hline Male & $\begin{array}{l}1.280 \\
(0.630-2.598)\end{array}$ & 0.495 & $\begin{array}{l}1.207 \\
(0.560-2.599)\end{array}$ & 0.631 & $\begin{array}{l}1.625 \\
(0.678-3.897)\end{array}$ & 0.277 & $\begin{array}{l}1.545 \\
(0.594-4.016)\end{array}$ & 0.372 \\
\hline Female & 1.00 & - & 1.00 & - & 1.00 & - & 1.00 & - \\
\hline \multicolumn{9}{|c|}{ Cytogenetics and Molecular Risk } \\
\hline Favorable & 1.00 & - & 1.00 & - & 1.00 & - & 1.00 & - \\
\hline Intermediate & $\begin{array}{l}1.459 \\
(0.501-4.252)\end{array}$ & 0.489 & $\begin{array}{l}1.573 \\
(0.469-5.280)\end{array}$ & 0.463 & $\begin{array}{l}4.190 \\
(0.555-31.654)\end{array}$ & 0.165 & $\begin{array}{l}2.743 \\
(0.294-25.590)\end{array}$ & 0.376 \\
\hline Adverse & $\begin{array}{l}1.538 \\
(0.433-5.462)\end{array}$ & 0.506 & $\begin{array}{l}1.809 \\
(0.484-6.768)\end{array}$ & 0.379 & $\begin{array}{l}4.011 \\
(0.446-36.050)\end{array}$ & 0.215 & $\begin{array}{l}6.744 \\
(0.676-67.256)\end{array}$ & 0.104 \\
\hline \multicolumn{9}{|c|}{ Number of Induction Therapy Courses to achieve MRD-negative CR } \\
\hline 1 & 1.00 & - & 1.00 & - & 1.00 & - & 1.00 & - \\
\hline More than 1 & $\begin{array}{l}0.743 \\
(0.359-1.539)\end{array}$ & 0.424 & $\begin{array}{l}0.655 \\
(0.286-1.498)\end{array}$ & 0.316 & $\begin{array}{l}0.686 \\
(0.284-1.660)\end{array}$ & 0.404 & $\begin{array}{l}0.494 \\
(0.188-1.295)\end{array}$ & 0.151 \\
\hline \multicolumn{9}{|l|}{ Consolidation Regimen } \\
\hline AML-87 & $\begin{array}{l}0.798 \\
(0.320-1.987)\end{array}$ & 0.627 & $\begin{array}{l}1.019 \\
(0.318-3.266)\end{array}$ & 0.975 & $\begin{array}{l}1.274 \\
(0.414-3.921)\end{array}$ & 0.673 & $\begin{array}{l}1.858 \\
(0.441-7.820)\end{array}$ & 0.398 \\
\hline AML-201 & $\begin{array}{l}0.652 \\
(0.252-1.687)\end{array}$ & 0.377 & $\begin{array}{l}0.892 \\
(0.320-2.488)\end{array}$ & 0.827 & $\begin{array}{l}0.372 \\
(0.093-1.493)\end{array}$ & 0.163 & $\begin{array}{l}0.374 \\
(0.088-1.592)\end{array}$ & 0.183 \\
\hline HDAra-C & 1.00 & - & 1.00 & - & 1.00 & - & 1.00 & - \\
\hline \multicolumn{9}{|l|}{$D_{P L T}$} \\
\hline Hlgh & 1.00 & - & 1.00 & - & 1.00 & - & 1.00 & - \\
\hline Low & $\begin{array}{l}3.106 \\
(1.509-6.394)\end{array}$ & 0.002 & $\begin{array}{l}2.894 \\
(1.320-6.345)\end{array}$ & 0.008 & $\begin{array}{l}2.525 \\
(1.056-6.035)\end{array}$ & 0.037 & $\begin{array}{l}3.077 \\
(1.130-8.376)\end{array}$ & .0 .028 \\
\hline
\end{tabular}

cohort is absent to test the robustness of the established cut-point. Secondly, the study is retrospectively designed. Our findings require further evaluation and confirmation in a larger-scale prospective study with independent testing and validation cohorts. However, our study provides a clear basis for further investigations of post-treatment response biomarkers.

The underlying mechanism of this phenomenon needs further exploration. Researchers found that marrow failure in AML patients is probably due to a differentiation block impeding hematopoietic stem cells in the leukemic marrow to produce sufficient progenitors, rather than the depletion of hematopoietic stem cells [23, 24]. Many existing studies have also reported the effect of leukemic microenvironment to promote leukemic cell proliferation and survival, and to suppress normal hematopoiesis [25-27]. In addition, AML patients with CRp (complete remission with platelet count $<100 \times 10^{9} / \mathrm{L}$ ) or $\mathrm{CRi}$ (complete remission with absolute neutrophil count < $1.0 \times 10^{9} / \mathrm{L}$ ) are observed to have higher MRD levels and poorer outcomes [3]. Based on these findings, we speculate that the degree of platelet count recovery $\left(D_{\text {PLT }}\right)$ may reflect the degree of remission and the improvement of the bone marrow microenvironment for normal hematopoiesis. This view is further supported by our observation that the signal for PFS is stronger compared to OS, suggesting better treatment response, but no ultimate cure (OS is influenced by more factors besides remission degree).

In previous studies, the platelet peak value after $C R$,

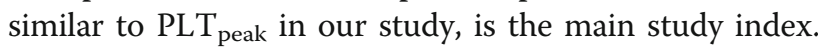
Here we chose $D_{\text {PLT }}$ as the prognostic indicator of clinical outcomes. We also explored the relationship between $\mathrm{PLT}_{\text {peak }}$ and PFS/OS for comparison. Again patients in high PLT $_{\text {peak }}$ group were found to have a better PFS and a better OS, but without statistical significance by cross validation. Our results showed that $\mathrm{D}_{\text {PLT }}$ rather than $\mathrm{PLT}_{\text {peak }}$ stratify differences of clinical outcomes better, especially for PFS. $D_{\text {PLT }}$ seems a better prognosis indicator than $\mathrm{PLT}_{\text {peak }}$ alone. Theoretically, by calculating the difference of platelet count between "before treatment" and "after CR" of the same patient, $D_{\text {PLT }}$ 
may at least partly reduce the bias caused by individual difference in overall platelet counts.

In this study, we determined the cut-point as $\mathrm{D}_{\mathrm{PLT}}=$ $212 \times 10^{9} / \mathrm{L}$ and test its significance by a cross validation analysis. We want to emphasize that the optimal cutpoint cannot be easily determined. Peripheral blood counts are influenced by many factors; hence, the normal platelet level of the patients before suffering from AML (though difficult to get) may also be valuable. Whether or not a positive correlation exists between platelet recovery degree and remission degree still remains unclear. Further exploration and careful clinical observation are needed to discover the true biological meaning of this phenomenon.

\section{Conclusions}

This study demonstrated that the degree of platelet recovery after achieving the first MRD-negative CR ( $\left.D_{\text {PLT }}\right)$ is a potential predictor of clinical outcomes, especially for PFS, in CR patients. Higher $D_{\text {PLT }}$ value is associated with longer PFS and OS. Our findings may help to develop simple methods for AML prognosis evaluation, although larger-scale prospective studies with independent testing and validation cohorts are required to further test our results.

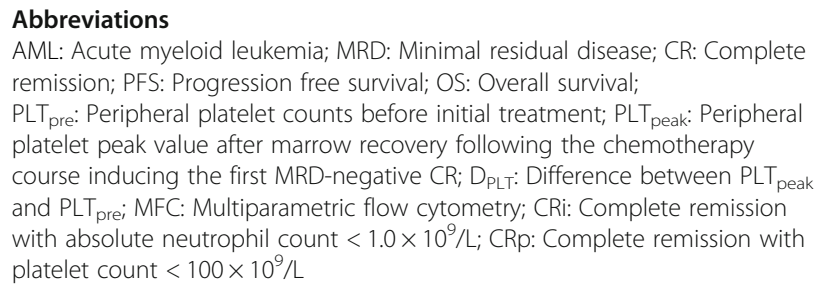
remission; PFS: Progression free survival; OS: Overall survival;

$P L T_{\text {pre: }}$ Peripheral platelet counts before initial treatment; $P L T_{\text {peak: }}$ Peripheral platelet peak value after marrow recovery following the chemotherapy course inducing the first MRD-negative CR; $D_{P L T}$ : Difference between PLT peak and PLT pre; MFC: Multiparametric flow cytometry; CRi: Complete remission with absolute neutrophil count $<1.0 \times 10^{9} / \mathrm{L}$; CRp: Complete remission with platelet count $<100 \times 10^{9} / \mathrm{L}$

\section{Acknowledgements}

Thanks the medical workers in Sun Yat-sen University Cancer Center for their management and care of the patients, and obtainment of the clinical data.

\author{
Authors' contributions \\ YW collected and analyzed the patient data and wrote the manuscript. HW \\ and $\mathrm{WW}$ analyzed the data and wrote the manuscript. WL, NL and SL \\ performed marrow aspiration, collected the data and wrote the manuscript. \\ $Y L$ designed the study and wrote the manuscript. All authors read and \\ approved the final manuscript. \\ Funding \\ Our work was funded by the following funds: \\ 1. National Natural Science Foundation of China, and the contract/grant \\ number is 30471976 and 81272620 . \\ 2. Science and technology projects of Guangdong Province, and the \\ contract/grant number is 2016A020215086.
}

\section{Availability of data and materials}

The datasets during and/or analysed during the current study available from the corresponding author on reasonable request.

\section{Ethics approval and consent to participate}

All procedures performed in studies involving human participants were in accordance with the ethical standards of the Ethical committee of the Sun Yat-sen University Cancer Center and with the 1964 Helsinki declaration and its later amendments or comparable ethical standards.
Written informed consent was obtained from all individual patients included in the study. This study was approved by the Ethical committee of the Sun Yat-sen University Cancer Center.

\section{Consent for publication}

Not applicable.

\section{Competing interests}

Our work was funded by the following funds:

1. National Natural Science Foundation of China, and the contract/grant number is 30471976 and 81272620 .

2. Science and technology projects of Guangdong Province, and the contract/grant number is 2016A020215086.

One of the authors, Hua Wang, is a member of the editorial board of BMC Cancer.

Received: 4 September 2019 Accepted: 27 July 2020

Published online: 05 August 2020

\section{References}

1. Vardiman JW, Thiele J, Arber DA, et al. The 2008 revision of the World Health Organization (WHO) classification of myeloid neoplasms and acute leukemia: rationale and important changes. Blood. 2009;114:937-51.

2. Arber DA, Orazi A, Hasserjian R, et al. The 2016 revision to the World Health Organization classification of myeloid neoplasms and acute leukemia. Blood. 2016;127:2391-405.

3. Chen X, Xie H, Wood BL, et al. Relation of clinical response and minimal residual disease and their prognostic impact on outcome in acute myeloid leukemia. J Clin Oncol. 2015;33:1258-64.

4. Cruz NM, Mencia-Trinchant N, Hassane DC, Guzman ML. Minimal residual disease in acute myelogenous leukemia. Int J Lab Hematol. 2017;39(suppl 1):53-60.

5. Wheatley K, Burnett AK, Goldstone AH, et al. A simple, robust, validated and highly predictive index for the determination of risk-directed therapy in acute myeloid leukemia derived from the MRC AML 10 trial. Br J Haematol. 1999;107:69-79.

6. Chen Y, Cortes J, Estrov Z, Faderl S, et al. Persistence of cytogenetic abnormalities at complete remission after introduction in patients with acute myeloid leukemia: prognostic significance and the potential role of allogeneic stem-cell transplantation. J Clin Oncol. 2011;29:2507-13.

7. Jaso JM, Wang SA, Jorgensen JL, Lin P. Multi-color flow cytometric immunophenotyping for detection of minimal residual disease in AML: past, present and future. Bone Marrow Transplant. 2014;49:1129-38.

8. Weisser M, Haferlach C, Hiddemann W, Schnittger S. The quality of molecular response to chemotherapy is predictive for the outcome of AML1-ETO-positive AML and is independent of pretreatment risk factors. Leukemia. 2017;21:1177-82.

9. Tallman MS, Gilliland DG, Rowe JM. Drug therapy for acute myeloid leukemia. Blood. 2005;106:1154-63.

10. Vardiman JW, Harris NL, Brunning RD. The World Health Organization (WHO) classification of the myeloid neoplasms. Blood. 2002;100:2292-302.

11. Miyawaki S, Ohtake S, Fujisawa S, et al. A randomized comparison of 4 courses of standard-dose multiagent chemotherapy versus 3 courses of high-dose cytarabine alone in postremission therapy for acute myeloid leukemia in adults: the JALSG AML201 study. Blood. 2011;117:2366-72.

12. Ohno R, Kobayashi T, Tanimoto M, et al. Randomized study of individualized induction therapy with or without vincristine, and of maintenanceintensification therapy between 4 or 12 courses in adult acute myeloid leukemia. AML-87 study of the Japan adult leukemia study group. Cancer. 1993;71:3888-95.

13. Mayer RJ, Davis RB, Schiffer CA, et al. Intensive postremission chemotherapy in adults with acute myeloid leukemia. Cancer and leukemia group B. N Engl J Med. 1994;331:896-903.

14. Camp RL, Dolled-Filhart M, Rimm DL. X-tile: a new bio-informatics tool for biomarker assessment and outcome-based cut-point optimization. Clin Cancer Res. 2004;10:7252-9.

15. Dolled-Filhart M, McCabe A, Giltnane J, et al. Quantitative in situ analysis of $\beta$-catenin expression in breast cancer shows decreased expression is associated with poor outcome. Cancer Res. 2006;66:5487-94.

16. Hilsenbeck SG, Clark GM, McGuire WL. Why do so many prognostic factors fail to pan out? Breast Cancer Res Treat. 1992;22:197-206. 
17. Faraggi D, Simon R. A simulation study of cross-validation for selecting an optimal cutpoint in univariate survival analysis. Stat Med. 1996;15:2203-13.

18. Kayser S, Walter RB, Stock W, Schlenk RF. Minimal residual disease in acute myeloid leukemia-current status and future perspectives. Curr Hematol Malig Rep. 2015;10:132-44.

19. Ossenkoppele G, Schuurhuis GJ. MRD in AML: does it already guide therapy decision-making? Hematology Am Soc Hematol Educ Program. 2016;2016: 356-65.

20. Ding L, Ley TJ, Larson DE, et al. Clonal evolution in relapsed acute myeloid leukemia revealed by whole-genome sequencing. Nature. 2012;481:506-10.

21. Yanada M, Borthakur G, Garcia-Manero G, Ravandi F, Faderl S, Pierce S, Kantarjian H, Estey E. Blood counts at time of complete remission provide additional independent prognostic information in acute myeloid leukemia. Leuk Res. 2008;32:1505-9.

22. Yamazaki $\mathrm{E}$, Kanamori $\mathrm{H}$, Itabashi M, et al. Hyper-recovery of platelets after induction therapy is a predictor of relapse-free survival in acute myeloid leukemia. Leuk Lymphoma. 2017;58:104-9.

23. Miraki-Mond F, Anjos-Afonso F, Hodby KA, et al. Acute myeloid leukemia does not deplete normal hematopoietic stem cells but induces cytopenias by impeding their differentiation. Proc Natl Acad Sci U S A. 2013;1 10:1357681

24. Werner B, Gallagher RE, Paietta EM, et al. Dynamics of leukemia stem-like cell extinction in acute promyelocytic leukemia. Cancer Res. 2014;74:538696.

25. Shafat MS, Gnaneswaran B, Bowles KM, Rushworth SA. The bone marrow microenvironment-home of the leukemic blasts. Blood Rev. 2017:31:277-86.

26. Kumar B, Garcia M, Weng L, et al. Acute myeloid leukemia transforms the bone marrow niche into a leukemia-permissive microenvironment through exosome secretion. Leukemia. 2018:32:575-87.

27. von der Heide EK, Neumann M, Vosberg S, et al. Molecular alterations in bone marrow mesenchymal stromal cells derived from acute myeloid leukemia patients. Leukemia. 2017;31:1069-78.

\section{Publisher's Note}

Springer Nature remains neutral with regard to jurisdictional claims in published maps and institutional affiliations.

Ready to submit your research? Choose BMC and benefit from:

- fast, convenient online submission

- thorough peer review by experienced researchers in your field

- rapid publication on acceptance

- support for research data, including large and complex data types

- gold Open Access which fosters wider collaboration and increased citations

- maximum visibility for your research: over $100 \mathrm{M}$ website views per year

At $\mathrm{BMC}$, research is always in progress.

Learn more biomedcentral.com/submissions 